\title{
X-linked intellectual disability, Seemanova type
}

INSERM

\section{Source}

INSERM. (1999). Orphanet: an online rare disease and orphan drug data base. $\underline{X-l i n k e d}$ intellectual disability, Seemanova type. ORPHA:85323

X-linked intellectual disability, Seemanova type is characterised by microcephaly, intellectual deficit, growth retardation and hypogenitalism. It has been described in four boys from one family. A characteristic facies and ophthalmologic anomalies were also present and included microphthalmia, microcornea and cataract. Transmission is Xlinked. 